\title{
AS CÓPIAS DE VERONESE POR FRANÇOIS BOUCHER DO ACERVO DO MUSEU DE ARTE DE SÃO PAULO
}

\author{
Maria Antonia Couto da Silva ${ }^{1}$
}

Nesta comunicação pretendemos analisar o contexto histórico e artístico em que foram realizadas duas telas pertencentes ao Museu de Arte de São Paulo ( MASP), cópias de quadros de Paolo Veronese (1528-1588), pintadas por François Boucher (1703-1770), intituladas Hércules entre o Vício e a Virtude [fig. 1] e Alegoria da Sabedoria e da Força [fig. 2]. O texto originou-se de pesquisa para dissertação de mestrado, realizada no Instituto de Filosofia e Ciências Humanas da Universidade Estadual de Campinas. ${ }^{2}$

Os quadros de Veronese foram pintados por volta de 1576 e pertencem atualmente à Frick Collection, de Nova York. As cópias pintadas por Boucher, provavelmente a pedido do duque de Aveiro, de Portugal, foram feitas quando os originais estavam na Coleção do Regente da França (Philippe II, duque de Orléans), sendo datadas de a partir de 1752.

Sobre os originais, a monografia de Peter Watson, de 1989, elucidou a trajetória do quadro Alegoria da Sabedoria e da Força, e ao tratar desta também narrou a história da obra Hércules entre o Vicio e a Virtude, desde sua criação em Veneza até o destino final na coleção de Nova York. ${ }^{3}$

As relações histórico-artísticas entre esses originais, realizados por um pintor veneziano do Renascimento, e suas cópias francesas do século XVIII revelaram-se fascinantes, questões que envolvem a história da arte, do gosto e do colecionismo.

O estudo dos quadros do MASP nos conduz também a uma reflexão que gira em torno do próprio conceito de cópia, tão negativo no século XX. A possibilidade de reprodução das imagens através de técnicas modernas e a própria visão romântica da inspiração podem ter colaborado para esta depreciação.

É importante lembrar que, ao longo da história da arte, a cópia era um exercício fundamental na formação dos artistas, como atividade de elevada significação estética ou como tributo a um determinado mestre. A partir do Maneirismo a cópia situou-se no centro do exercício artístico, "aos pintores cabendo copiar outros pintores, arquitetura e a natureza, nessa ordem hierárquica”. " ${ }^{4}$ É preciso lembrar que a cópia não é um fenômeno histórico-artístico arbitrário, cada época escolhe seus mestres. Veronese, por outro lado, foi amplamente copiado por artistas de todos os tempos: Rubens, Francesco Guardi, Tiepolo, Sebastiano Ricci e François Boucher, entre outros.

Dos originais de Veronese são conhecidas quatro cópias: as primeiras foram realizadas em torno de 1655 e estão no Kunsthistoriches Museum, em Viena. François Boucher realizou a segunda cópia dos quadros quase cem anos após as primeiras. A terceira cópia foi feita por Carle van Loo, que se tornou o principal pintor do rei, em 1762, e diretor da Academia Francesa um ano depois; os quadros estão atualmente no museu de Cambrai, na França. A quarta cópia, talvez do fim do século XVIII, só tornou-se conhecida

\footnotetext{
${ }^{1}$ Doutoranda pelo IFCH/UNICAMP

2 SILVA, Maria Antonia Couto da. As cópias de Veronese por François Boucher, do acervo do Museu de Arte de São Paulo. Dissertação (mestrado), Universidade Estadual de Campinas, Instituto de Filosofia e Ciências Humanas. UNICAMP, IFCH. (Orientador: Prof. Dr. Luiz César Marques Filho). Campinas, SP: [s.n.], 2003.

3 WATSON, P. Wisdom and Strength: The Biography of a Renaissance Masterpiece. New York, Doubleday, 1989.

${ }^{4}$ MARQUES, Luiz. “De onde nasce um museu”. Revista Galeria, São Paulo, n.18, 1990, p.90.
} 
em 1971, quando o Marquês de Bute, da Escócia, visitou a Frick Collection e viu o original de uma pintura que pertencera a um ancestral seu. A autoria destas pinturas é desconhecida, segundo Peter Watson os quadros foram exibidos pela primeira vez na Inglaterra em 1799, o que sugere serem também cópias do século XVIII. ${ }^{5}$

No caso das obras do MASP, como nota Marques, mesmo Michel Laclotte, que foi diretor do Louvre, manifestou ao vê-las "certa perplexidade, motivada sobretudo pelo fato de que Boucher soube, ao copiar Veronese, mimetizar perfeitamente a técnica da pintura veneziana do século XVI". 6

Essas cópias de Veronese do século XVIII pertencem a um contexto histórico de revalorização européia da pintura veneziana do Renascimento. A retomada da poética dos mestres venezianos ocorreu não somente por meio de Sebastiano Ricci, que reverenciou especialmente a obra de Veronese, mas também pela divulgação das pinturas de Rubens no ambiente francês, que pode ser percebida na produção de artistas como Antoine Watteau.

$\mathrm{Na}$ França, desde o final do século XVII, os membros da Real Academia de Pintura e Escultura estiveram envolvidos em um debate entre dois grupos específicos, os partidários de Poussin e os de Rubens, que defendiam, de um lado, a soberania do desenho e, de outro, a da cor. O pintor Charles Le Brun, diretor da Real Academia, defendia a tradição relacionada à pintura de história, elegendo Poussin como modelo a ser seguido pelos outros pintores. Le Brun destacava na pintura a importância do desenho e da expressão dos afetos, considerando a cor "menos nobre que o desenho".

A partir de 1673, com a publicação do Dialogue sur le coloris, de Roger de Piles, o debate se acirrou. A norma acadêmica começou a ser questionada, sob o impacto do ciclo de Rubens sobre a vida de Maria de Medicis, exposto no Palácio Luxemburgo.

Com a obra de Rubens, a Paris do século XVIII redescobriu a sensibilidade cromática veneziana e a poética de seus mestres do Renascimento. O conhecimento dos modelos italianos na França ocorreu com a divulgação de coleções de arte, como as de Crozat e Mariette, por meio da reprodução das obras, principalmente em gravuras. A coleção do regente da França, Philippe II, duque de Orléans, foi fundamental neste sentido, porque possuía muitas pinturas de artistas venezianos e várias obras de Veronese, entre estas, os quadros por nós estudados.

Crozat e o regente reuniram um círculo de amadores e colecionadores de arte, também freqüentado por artistas, que tinham acesso a suas coleções, contribuindo assim para a formação do gosto por quadros italianos e, mais especificamente, venezianos.

Além da relação com o contexto artístico de revalorização da obra dos mestres venezianos do Renascimento, os quadros copiados por Boucher merecem destaque também em relação à iconografia apresentada, que comentaremos brevemente.

\section{Considerações sobre a iconografia das obras}

As alegorias realizadas provavelmente para Rodolfo II estão entre as obras-primas de Veronese. O quadro A escolha de Hércules ou Hércules entre o Vicio e a Virtude é uma variação sobre uma temática cara aos pintores do Renascimento.

De acordo com o ensaio de Erwin Panofsky ${ }^{7}$, o mito da escolha de Hércules é narrado por Pródico, e sua versão mais antiga foi transmitida por Xenofonte, em

\footnotetext{
${ }^{5}$ WATSON, op.cit., p. 210.

${ }^{6}$ MARQUES, Luiz. Op. cit., p. 91.

7 PANOFSKY, Erwin. Hercule à la croisée des chemins. Paris, Flammarion, 1999. [Original: Hercules am Scheidewege und andere antike Bildstoffe in neueren Kunst, Leipzig; Berlin, B.G. Teubner, 1930].
} 
Memorabilia, II, 1, 21-33: Hércules, jovem, repleto de dúvidas, estava refletindo em um local isolado e não muito preciso. Surgem duas mulheres que se dirigem a ele, procurando arrebatar o jovem, prometendo, cada uma a seu modo, conduzi-lo à felicidade. A primeira, que representa o Vício, promete um caminho mais agradável e fácil, por sua alegria e ociosidade; a segunda, associada à Virtude, indica uma rota longa e difícil, repleta de privações e perigo. A escolha de Hércules é conhecida: ele decide-se pela Virtude.

O personagem assumiu uma surpreendente multiplicidade de papéis no campo filosófico, em textos ligados aos pitagóricos, estóicos e sofistas, sendo sua trajetória utilizada como uma metáfora da condição humana.

A representação de Veronese teria como base uma versão da narrativa do mito relatada na Vida de Apolônio de Tiana, escrita por Filóstrato. O texto teve a primeira tradução latina impressa em 1501, e tornou-se muito conhecido no início do século XVI. Filóstrato opõe a Volúpia, ornada com colares de ouro, cabelos cuidadosamente trançados e calçando sandálias de ouro, à Virtude, que tem os pés descalços e um aspecto negligente. ${ }^{8}$

Como nota ainda Panofsky, entre os textos antigos, Filóstrato é a única fonte em que encontramos o motivo das duas mulheres que tentam puxar Hércules, efetivamente, cada uma para seu lado, procurando convencê-lo não só pelas palavras e pelo olhar, como aparece na descrição de Xenofonte, mas também por meio de gestos e até da força.

Em seu ensaio, Panofsky demonstrou que o quadro Hércules entre o Vicio e a Virtude foi realizado com muita liberdade em relação à iconografia utilizada pelos artistas anteriores a Veronese. Nesta composição, o herói, de vestes argênteas (um suposto retrato de Veronese), abandona a jovem ricamente enfeitada e precipita-se nos braços da outra, de aspecto mais severo, que porta uma coroa de louros e representa a Virtude.

O espaço no quadro avança em diagonal, a composição é equilibrada pela oposição de uma coluna com uma cariátide, à esquerda e uma árvore à direita. $\mathrm{Na}$ arquitrave sustentada pela cariátide vê-se a inscrição "[HO]NOR ET VIRTUS [P]OST MORTEM FLORET” (Honra e Virtude florescem após a morte). A representação enfatiza, portanto, a questão da imortalidade ligada à escolha de uma vida virtuosa. Destaca-se nesta pintura a luminosidade alta, diurna, que se estende pelo espaço aberto. Neste quadro Veronese enfatiza a cena, aproximada aos olhos do espectador, em que Hércules faz sua escolha.

Já o quadro Alegoria da Sabedoria e da Força pode ser considerado um desdobramento do tema de Hércules entre o Vicio e a Virtude. A personagem feminina, que representa a Sabedoria, volta os olhos para o firmamento e tem como atributo o sol que resplandece sobre si. É uma figura sinuosa, que deriva da estatuária antiga. Sua superioridade sobre o mundo material não é somente sugerida pelo globo terrestre sobre o qual repousa seu pé e pelas riquezas, dispersas ao sol, mas pelo ar pensativo do segundo personagem, Hércules, instavelmente apoiado em sua clave. Inspirado, do ponto de vista formal, na escultura intitulada Hércules Farnese (cópia romana de obra provavelmente do escultor grego Lisipo, descoberta em Roma na década de 1540), o herói está acompanhado de seus atributos - o manto de Neméia e a clava - e tem um ar melancólico; volta os olhos para o chão, onde estão depositadas riquezas. Ambos estão em primeiro plano. À esquerda o espaço estendese em uma paisagem distante, e a luminosidade é a do amanhecer. $\mathrm{Na}$ base da coluna está a citação OMNIA VANITAS (Tudo é vaidade). A iconografia da Vanitas, relacionada à fugacidade da vida, tornou-se recorrente durante o século XVII.

${ }^{8}$ Filóstrato, Memorabilia,VI, 10, Apud Panofsky, Erwin. Op. cit., p. 100-2. 
Este quadro pode se visto como um desdobramento da escolha de Hércules, em que este se submete à Virtude, aqui, com a concepção do Renascimento, associada à Sabedoria.

Veronese, em ambos os quadros, faz referências à escolha do caminho virtuoso, utilizando uma temática que é, ao mesmo tempo, erótica e moralizante.

Como nota Panofsky o tema da escolha de Hércules encontrou sua forma canônica posteriormente na obra de Annibale Carracci, realizada em 1596 (Museo Nazionale di Capodimonte, Nápoles). O quadro de Carracci tornou-se um modelo para a representação do tema, e a maioria dos artistas posteriores, até o século XVIII, estabeleceram com este uma relação de concordância ou oposição. Neste quadro Hércules é representado sentado, escutando o discurso da Virtude, que porta uma curta espada. A oposição entre as figuras femininas dá-se através das vestes e dos cabelos mais sóbrios da Virtude e cuidadosamente trançados da Volúpia.

$\mathrm{Na}$ opinião de Panofsky, a pintura de Carracci procurou a "reconstrução de uma Antiguidade ideal" através de um ritmo harmonioso; o artista representou com o mínimo de movimento um instante de vida interior extremamente intenso. O quadro de Carracci distinguiu-se por uma "idealidade atemporal"; nisto opôs-se a um "realismo de época" presente na obra de Veronese. ${ }^{9}$

Devemos notar que as pinturas de Veronese podem ter representado um modelo interessante no século XVIII, por apresentarem uma iconografia não usual. O artista pintou dois momentos posteriores às cenas representadas mais freqüentemente. $\mathrm{Na}$ obra Hércules entre o Vicio e a Virtude, Veronese apresentou o personagem no momento em que ele realiza sua escolha e se atira voluntariamente nos braços da Virtude.

As duas obras de Paolo Veronese apresentam modelos de iconografia política que foram associados à figura dos governantes, o que justifica o fato de terem pertencido a uma tradição de colecionismo ligada aos soberanos e ao poder. Devemos lembrar a trajetória desses quadros, que pertenceram sucessivamente a Rodolfo II, imperador habsburgo, à rainha Cristina, da Suécia, e posteriormente ao regente da França. Isso justificaria também o interesse nas cópias realizadas provavelmente para o duque de Aveiro, um nobre ligado ao rei D. João V, de Portugal. ${ }^{10}$

Além da temática dos quadros, obras de pintores venezianos como Tiziano e Veronese constituíram-se em modelos para os artistas franceses, desde o início do século XVIII. Estes quadros foram muito procurados por colecionadores e suas cópias valorizadas, como a coleção de Pierre Crozat o demonstrou. Esta redescoberta dos mestres venezianos esteve ligada aos debates em torno da supremacia do desenho ou da cor, ocorridos na Academia Francesa, no século XVII, que comentarei a seguir.

\section{A polêmica desenho $\mathrm{x}$ colorido}

Na França, a Real Academia de Pintura e Escultura, fundada em 1648, possuía a finalidade não apenas de formação dos artistas, mas de estabelecer reflexões sobre a arte. A

\footnotetext{
9 PANOFSKY, op. cit., p. 120.

10 A documentação existente no Museu de Arte de São Paulo, relacionada às duas cópias de Boucher, menciona o duque de Aneiro como o encomendante dos quadros e diz que, após sua morte, elas tornaram-se "propriedade da família de Bragança, que estava reinando em Portugal" (carta de Mithchell Samuels a Assis Chateaubriand, 05/04/1951). Nos dicionários e livros de história de Portugal consultados, não encontrei referências ao duque de Aneiro. Em minha dissertação parti da hipótese de que o encomendante teria sido José de Mascarenhas, duque de Aveiro, por sua representatividade em Portugal naquele período.
} 
Academia Francesa constituiu uma tradição ligada à pintura de história e à tradição do desenho de Poussin. Desenho e expressão eram a base da pintura, a cor não era considerada senão um acidente. O pintor Charles Le Brun, diretor da Academia, afirmava que a cor "depende inteiramente da matéria e, por conseguinte, é menos nobre do que o desenho, que depende só do espírito" ${ }^{\text {11 }}$. O debate sobre o colorido inseriu-se, então, em uma instituição cuja ordem e funcionamento haviam sido assegurados, desde a sua fundação, pelos partidários do desenho.

A polêmica iniciou-se com uma conferência de Philippe de Champaigne, em 1671, sobre um quadro de Tiziano. Seguiram-se discussões apaixonadas contra e a favor dos mestres venezianos. Le Brun formulou o pensamento da Academia, declarando que não se deveria negligenciar a cor e sim estudá-la com atenção e aplicação; entretanto seria conveniente fazê-lo "de forma que o desenho seja sempre o pólo e a bússola que nos rege" ${ }^{" 12}$. Roger de Piles, que participava das conferências como amador e iria tornar-se o grande defensor dos coloristas, decidiu levar o debate ao público e redigiu seu livro Dialogue sur le Coloris, impresso em 1673.

Um segundo episódio na polêmica teria ocorrido nos anos posteriores, entre $1676 \mathrm{e}$ 1681. Após ter perdido sua coleção de pinturas para o Rei (dentre elas, muitos quadros de Poussin), o duque de Richelieu a refizera com uma considerável série de obras de Rubens, organizada sob a orientação de Roger de Piles, que realizou um texto descrevendo a coleção. A discussão em torno da importância da cor e do colorido foi reavivada na Academia. Roger de Piles levou o debate ao grande público, divulgando textos em que comentava estas questões, e tratando também, especificamente, das pinturas de Rubens.

A discussão já era antiga. No século XVI, Giorgio Vasari e Lodovico Dolce escreveram a respeito da primazia do desenho ou da cor. Podemos reconhecer no contexto francês a retomada das idéias presentes no debate italiano, do século XVI. Jacqueline Lichtenstein destaca pressupostos comuns aos partidários do desenho ou da cor, em ambos os contextos históricos, na Itália, no século XVI e na França, no fim do século XVII ${ }^{13}$. Nos dois momentos reivindicou-se o status e o saber do pintor, sem o qual seu ofício seria destituído de dignidade. Na França, porém, a Academia forçou a organização de uma teoria e levou à radicalização dos postulados teóricos.

Como conseqüência dos debates na academia, a obra de Rubens foi muito estudada pelos artistas franceses, em especial o ciclo de Maria de Medicis, realizado no Palácio do Luxemburgo entre 1621 e 1625. Como destacou Marques: "É em parte através do colorismo de Rubens que a Paris de fins do século XVII e início do XVIII redescobre a sensibilidade cromática, a lição veneziana, elegendo Tiziano e Veronese como os maiores pintores do Renascimento". ${ }^{14}$

Esses mestres venezianos foram fundamentais para a poética de artistas franceses como Watteau e Boucher, como pode ser percebido na fatura estruturada pelo colorido, na pincelada livre e em alguns temas tratados. Os escritos de Roger de Piles e o elogio ao colorido veneziano influenciaram também na formação de grandes coleções parisienses,

\footnotetext{
11 Le Brun, Sentiments sur le discours de M. Blanchard: 1672 apud LICHTEINSTEIN, Jaqueline. $A$ cor eloquënte. São Paulo, Siciliano, 1994, p.157.

12 Conforme MIROT, Léon. "Roger de Piles, critique d'art". III - L’oeuvre de Roger de Piles". Paris, Revue des Études Historiques, 1923, n.6, p. 24.

${ }^{13}$ LICHTEINSTEIN, Jaqueline. A cor eloquënte. São Paulo, Siciliano, 1994, p.157.

${ }^{14}$ MARQUES, Luiz. Op. cit., p. 91.
} 
como a de Pierre Crozat ${ }^{15}$ e também na de Philippe II de Orléans, a quem pertenceram os originais dos quadros copiados por Boucher, que foram objeto de nosso estudo.

Procurei comentar neste artigo, ainda que de forma bastante breve, a relevância do ponto de vista da iconografia e o contexto cultural no qual se inserem os dois quadros estudados. Como nota Marques, pelos motivos abordados, as cópias de Veronese por François Boucher pertencentes ao acervo do MASP assumem, assim, do ponto de vista histórico-artístico, um caráter paradigmático. ${ }^{16}$

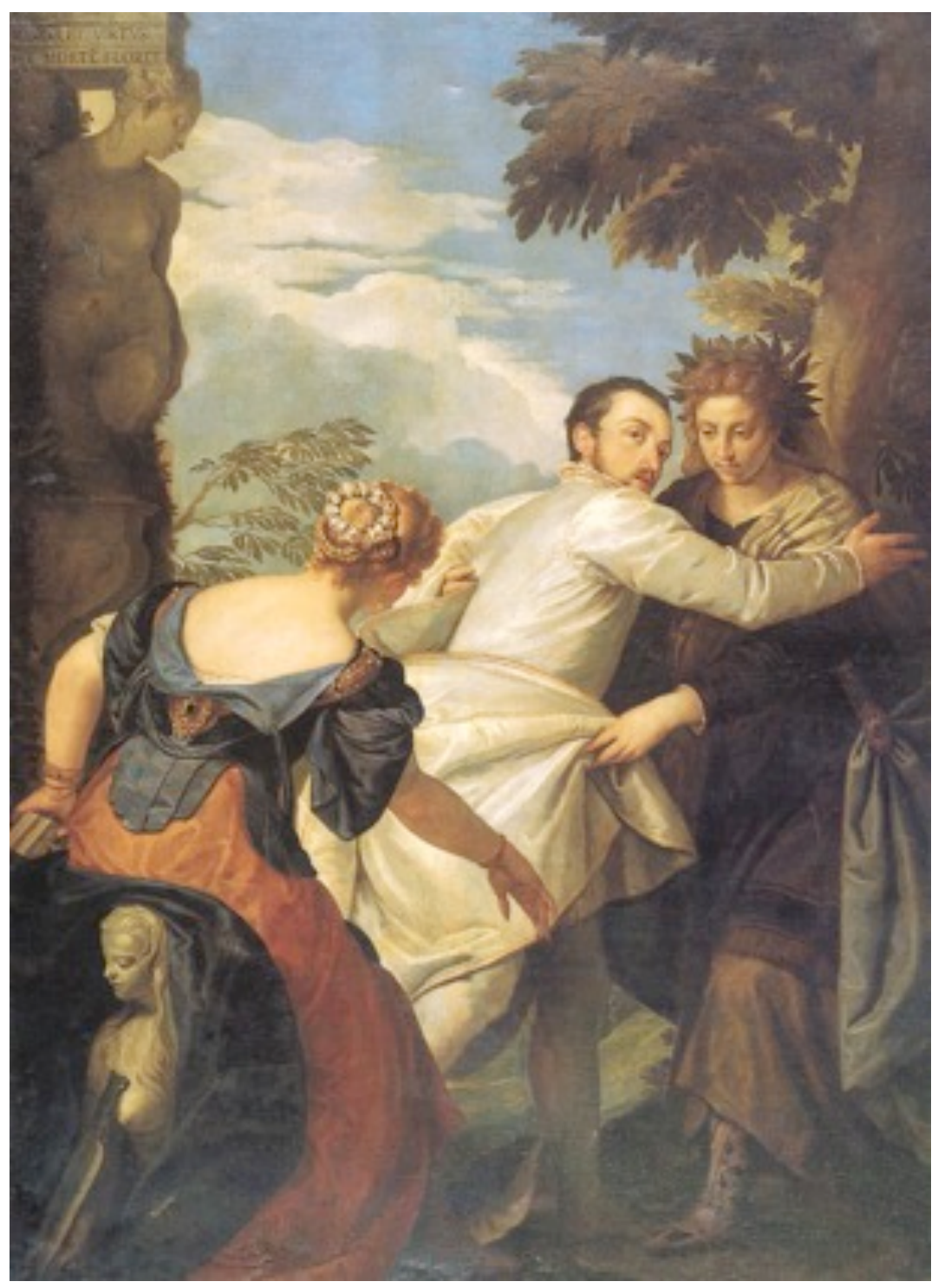

[Fig 1] François Boucher (cópia do quadro de Veronese), Hércules entre o Vício e a Virtude (ca.1752). óleo sobre tela, 223 x $171 \mathrm{~cm}$. Museu de Arte de São Paulo, São Paulo. Foto: Luiz Hossaka.

15 Conforme artigo de STUFFMANN, Margret. "Les tableaux de la collection de Pierre Crozat", Gazette des Beaux-Arts, Paris, 72, jun-set, 1968.

${ }^{16}$ MARQUES, Luiz. Op. cit., p. 91. 


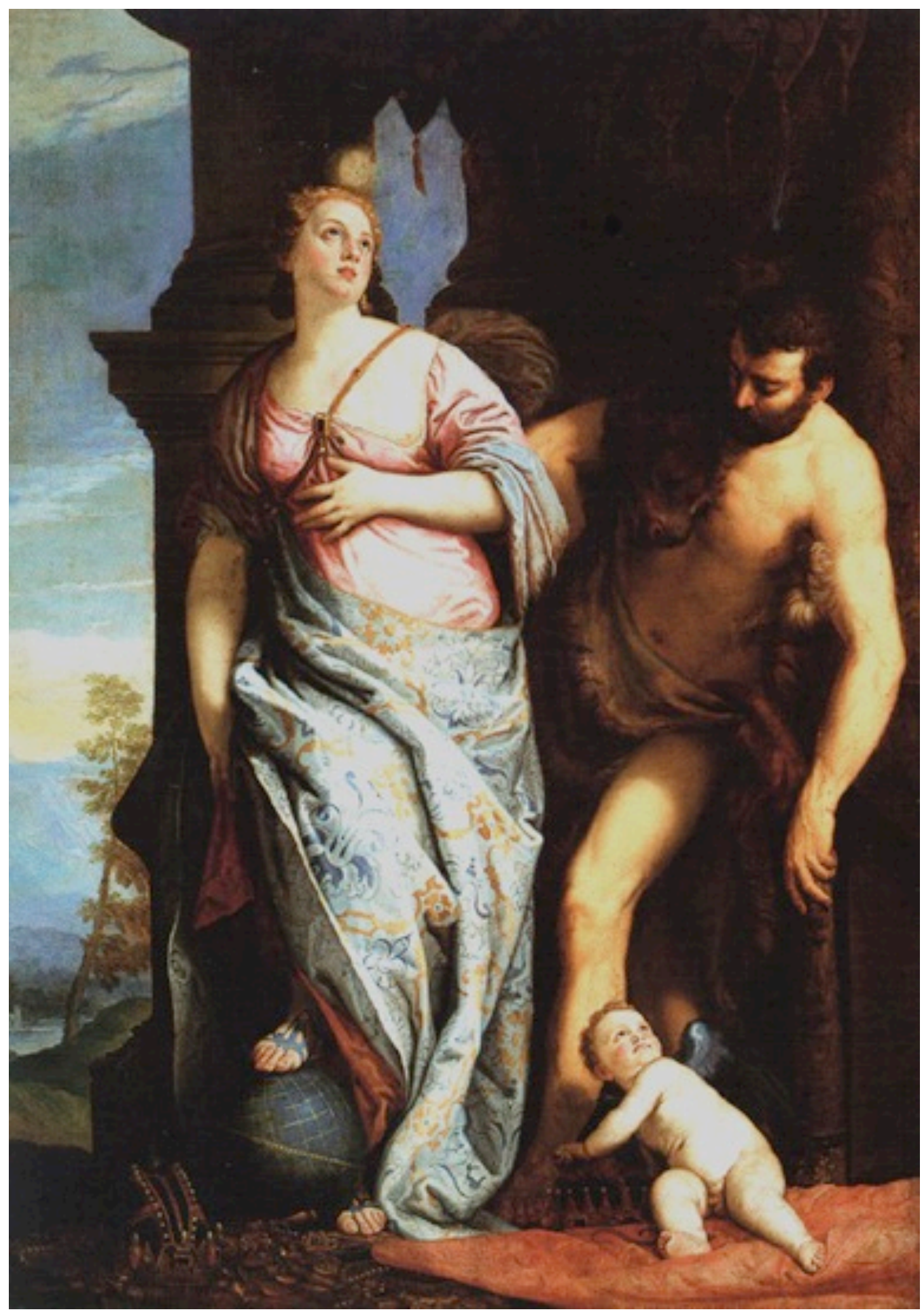

[Fig. 2] François Boucher, (cópia do quadro de Veronese), Alegoria da Sabedoria e da Forra (ca.1752). óleo sobre tela, $223 \times 171 \mathrm{~cm}$. Museu de Arte de São Paulo, São Paulo. Foto: Luiz Hossaka 